Nanopore metagenomics enables rapid clinical diagnosis of bacterial lower respiratory infection

Themoula Charalampous ${ }^{1 *}$, Gemma L. Kay ${ }^{1,2 *}$, Hollian Richardson ${ }^{1 *}$, Alp Aydin ${ }^{2}$, Rossella Baldan $^{1,3}$, Christopher Jeanes ${ }^{4}$, Duncan Rae ${ }^{4}$, Sara Grundy ${ }^{4}$, Daniel J. Turner ${ }^{5}$, John Wain $^{1,2}$, Richard M. Leggett ${ }^{6}$, David M. Livermore ${ }^{1,7}$ and Justin O'Grady ${ }^{1,2^{\wedge}}$

${ }^{1}$ Bob Champion Research and Educational Building, University of East Anglia, Norwich Research Park, Colney Ln, Norwich, UK, NR4 7UQ

${ }^{2}$ Quadram Institute Bioscience, Norwich Research Park, Colney Ln, Norwich, UK, NR4 7UA

${ }^{3}$ CIDR, King's College London, St Thomas' Hospital, Westminster Bridge Road, London, UK, SE1 7EH

${ }^{4}$ Microbiology Department, Norwich and Norfolk University Hospital, Conley Ln, Norwich, UK, NR4 7GJ

${ }^{5}$ Oxford Nanopore Technologies, Gosling Building, Oxford Science Park, Edmund Halley Rd, Oxford, UK, OX4 4DQ

${ }^{6}$ Earlham Institute, Norwich Research Park, Conley Ln, Norwich, UK, NR4 7UZ ${ }^{7}$ AMRHAI, Public Health England, 61 Colindale Ave, London, NW9 5EQ

${ }^{\wedge}$ Correspondence to justin.ogrady@quadram.ac.uk

*These authors contributed equally to this work: TC, HR, GLK

\title{
Editors summary
}

Nanopore sequencing coupled with a metagenomics framework that effectively removes human DNA from samples enables rapid bacterial LRI diagnosis. 


\section{ABSTRACT}

The gold standard for clinical diagnosis of bacterial lower respiratory infections (LRIs) is culture, which has poor sensitivity and is too slow to guide early, targeted antimicrobial therapy. Metagenomic sequencing could identify LRI pathogens much faster than culture, but methods are needed to remove the large amount of human DNA present in these samples for this approach to be feasible. We developed a metagenomics method for bacterial LRI diagnosis that features efficient saponinbased host DNA depletion and nanopore sequencing. Our pilot method was tested on 40 samples, then optimized, and tested on a further 41 samples. Our optimised method ( 6 hours from sample to result) was $96.6 \%$ sensitive and $41.7 \%$ specific for pathogen detection compared to culture and we could accurately detect antibioticresistance genes. After confirmatory $\mathrm{qPCR}$ and pathobiont-specific gene analyses, specificity and sensitivity increased to $100 \%$. Nanopore metagenomics can rapidly and accurately characterise bacterial LRIs and might contribute to a reduction in broad-spectrum antibiotic use. 


\section{INTRODUCTION}

Lower respiratory infections (LRIs) caused at least three million deaths worldwide in 2016 (http://www.who.int/news-room/fact-sheets/detail/the-top-10-causes-of-death). They can be subdivided into community-acquired pneumonia (CAP), hospital-acquired pneumonia (HAP), bronchitis, bronchiolitis and tracheitis ${ }^{1}$. Morbidity and mortality rates vary dependent on infection site, pathogen and host factors. In the UK, CAP accounts for approx. 29,000 deaths per annum and in the US HAP causes approx. 36,000 deaths per annum ${ }^{2,3}$. The most common bacterial CAP pathogens are Streptococcus pneumoniae and Haemophilus influenzae, and the most common HAP pathogens are Staphylococcus aureus, Enterobacteriaceae and Pseudomonas aeruginosa ${ }^{4-6}$. However, multiple bacterial and viral pathogen, can cause LRIs, which makes diagnosis and treatment a challenge.

Respiratory tract infections account for $60 \%$ of all antibiotics prescribed in general practice in the UK ${ }^{1}$. Initial treatment for severe LRIs usually involves empirical broadspectrum antibiotics. Guidelines recommend that such therapy should be refined or stopped after two to three days, once microbiology results become available ${ }^{7,8}$, but this is often not done if the patient is responding well or the laboratory has failed to identify a pathogen. Such extensive 'blind' use of broad-spectrum antibiotics is wasteful and constitutes poor stewardship, given that many patients are infected with susceptible bacteria or a virus. Antimicrobial therapy disrupts resident gut flora, and can contribute to the emergence of resistant bacteria and Clostridium difficile ${ }^{9,10}$.

Rapid and accurate microbiological diagnostics could enable tailored treatments and reduce overuse of broad-spectrum antibiotics. "Gold standard" culture and susceptibility testing is too slow, with typical turnaround times of $48-72$ hours and low clinical sensitivity 4 , 11. Molecular methods may help overcome the limitations of culture, as highlighted by the UK Government 5-year AMR action plan and the O'Neill report ${ }^{12-14}$, by identifying pathogens and their antibiotic resistance profiles in a few hours, enabling early targeted therapy and supporting antibiotic stewardship. Although nucleic acid amplification tests (including PCR) are rapid and highly specific/sensitive, there are limits on multiplexing ${ }^{15-19}$ and there is also a 
constant need to update PCR-based methods to include emerging resistance genes and mutations ${ }^{16,20,21 .}$

Metagenomic sequencing based approaches have the potential to overcome the shortcomings of both culture and PCR, by combining speed with comprehensive coverage of all microorganisms present ${ }^{22,23}$. Next-generation sequencting platforms, such as lon Torrent and Illumina, are widely used for metagenomics sequencing, but they require the sequencing run to be complete before analysis can begin (although LiveKraken, a recently described method, enables analysis of raw Illumina data before the run ends ${ }^{24}$ ). Nanopore sequencing (Oxford Nanopore Technologies, ONT) has the advantage of rapid library preparation and real-time data acquisition ${ }^{25,26}$. Nanopore sequencing has been used to identify viral and bacterial pathogens from clinical samples using targeted approaches and in proof-of-concept studies using samples with high pathogen loads e.g. urinary tract infection 26-28.

Respiratory specimens present a difficult challenge for metagenomics sequencing, owing to variable pathogen load, the presence of commensal respiratory tract flora, and the high ratio of host:pathogen nucleic acids present (up to 105:1 in sputum). Nanopore sequencing has previously been used for samples from two bacterial pneumonia patients without host cell/DNA depletion, but the vast majority of reads were of human origin, with only one and two reads aligned to the infecting pathogens, $P$. aeruginosa and $S$. aureus, respectively ${ }^{29}$. It seems likely that a metagenomics method would be improved by introducing host DNA depletion. Although commercial kits and published methods are available for this purpose (which include differential lysis, human DNA removal and microbial DNA enrichment methods ${ }^{30-33}$ ), they do not perform well in complex respiratory samples and better methods are needed ${ }^{34}$.

We present an optimised clinical nanopore metagenomics framework for bacterial LRIs that can remove up to $99.99 \%$ of host nucleic acid from clinical respiratory samples, and enables pathogen and antibiotic resistance gene identification within six hours. 


\section{RESULTS}

\section{Pilot method development}

A pilot method was tested on respiratory samples from 40 patients with suspected bacterial LRI. This method was $91.2 \%$ sensitive (95\% Cl; $75.2-97.7 \%)$ and $100 \%$ specific $(95 \% \mathrm{Cl}$; $54.07-100 \%$ ), not counting additional organisms in culture-positive samples as false positives (Table 1), and took 8 hours to perform (Figure 1). Up to $99.9 \%$ or $\sim 10^{3}$ fold (median 352-fold, interquartile range 144-714; maximum 1024-fold) of host DNA was removed using saponin depletion, as measured by qPCR. Microorganisms, including potential respiratory pathogens (Online methods), were identified in real-time using ONT's 'What's In My Pot?' (WIMP) pipeline. Additional pathogens, not reported by microbiological culture, were detected in 5/40 samples: Moraxella catarrhalis was detected in P8; Escherichia coli in P14; H. influenzae in P22 and P30; Klebsiella pneumoniae and M. catarrhalis in P29 (Table 1).

Organisms cultured using routine clinical microbiology were not detected in 3/40 sequenced samples. 2/3 samples were mixed infections, where one of the two pathogens present was missed by our pilot method - specifically, S. pneumoniae and $H$. influenzae were not detected in P3 and P37 respectively. S. aureus was not detected in the third sample, P34.

\section{Metagenomics protocol optimisation}

We sought to increase sensitivity ( $8.8 \%$ false negative rate) by improving bacterial cell lysis. A sample pre-treatment step was introduced (bead-beating or an enzyme cocktail, Online methods) to optimise cell lysis. Two culture-positive sputa were used for optimisation experiments, one containing $S$. aureus (Gram-positive) and one containing $P$. aeruginosa (Gram-negative). Neither pre-treatment affected the bacterial DNA yield in the $P$. aeruginosa sample. The enzyme cocktail increased the amount of bacterial DNA in the $S$. aureus sample by approx. 4 -fold, and bead-beating by 21 -fold, compared with the pilot method, as determined by $16 \mathrm{~S}$ qPCR (Supplementary Table 1a). The increased bacterial DNA yield in the bead-beaten $S$. aureus sample was likely to have been associated with improved lysis of 
S. aureus, as the pathogen dominated the bacterial community (approx. $80 \%$ of reads) present in the sample. We included bead-beating in the optimised method. Removal of the second DNase treatment and reducing the number of washes shortened the host DNA removal protocol from 90 min to 50 min, without affecting efficiency (Supplementary Table 1a). Additional time was saved by reducing the library preparation PCR extension time from six to four minutes. Comparison of the microbial community profile (organisms with $\geq 0.5 \%$ classified reads) between libraries produced with four and six minute extension times showed only minor differences in the abundance of minor members of the community and a small reduction in average read length for the $S$. aureus sample (<600bp) (Supplementary Table $1 \mathrm{~b})$. Altogether these changes reduced metagenomic library preparation to 2.5 hours with an overall turnaround time of less than four hours before DNA sequencing.

\section{Limit of detection}

The limit-of-detection (LoD) of the optimised method was determined using uninfected 'normal respiratory flora' (NRF) sputum samples (high and low commensal bacterial backgrounds in triplicate) spiked with serial ten-fold dilutions of $S$. aureus and $E$. coli cultures at known cell densities. Each replicate was defined as positive for the spiked 'pathogen' if present at $\geq 1 \%$ classified microbial reads (low quality read alignments with a WIMP assignment q-score $<20$ were removed from the analysis). The LoD ( $\geq 2 / 3$ replicates positive) was determined to be $100,000\left(10^{5}\right)$ cells for E. coli and $10,000\left(10^{4}\right)$ cells for $S$. aureus when in a high bacterial background (Supplementary Table 2a). The LoD was lower $\left(10^{3} \mathrm{~S}\right.$. aureus and E. coli) in sputum samples with a lower bacterial background (Supplementary Table $2 \mathrm{~b}$ ). Hence, the LoD of the method ranges from $10^{3}-10^{5} \mathrm{CFU} / \mathrm{ml}$, however, different levels of background commensal/human DNA could potentially result in different LoDs. 


\section{Mock community detection}

Our optimised method was tested in triplicate on a panel of common respiratory pathogens spiked into an NRF sputum sample $\left(\sim 10^{3}-10^{6} \mathrm{CFU} /\right.$ pathogen) to determine whether the saponin human DNA depletion method led to inadvertent loss of any bacterial DNA. We observed no bacterial DNA loss (average $\Delta \mathrm{Cq}<1)$ for any organisms $(E$. coli, H. influenzae, K. pneumoniae, $P$. aeruginosa, S. aureus and S. maltophilia) tested except S. pneumoniae where there was a 5.7-fold loss, (average $\Delta \mathrm{Cq} 2.52$ ) between depleted and undepleted samples (Supplementary Table 3).

\section{Optimised method testing}

The optimised method was then tested on 41 respiratory samples from patients with suspected bacterial LRIs. A maximum of $10^{4}$ fold depletion of human DNA (median 600-fold; interquartile range 168-1156 fold; maximum 18,054 fold) was observed between depleted and undepleted samples, as measured by qPCR (Table 2). The overall sensitivity of the optimised method for the detection of respiratory pathogens was $96.6 \%(95 \% \mathrm{Cl}, 80.4-$ $99.8 \%)$ and specificity was $41.7 \%(95 \% \mathrm{Cl}, 16.5-71.4 \%)$, not counting additional organisms in culture-positive samples as false positives (Table 2). The turnaround time from sample to result was approx. 6 hours, including 2 hours MinION sequencing (Supplementary Table 4).

The pathogenic organism reported by routine microbiology was detected together with an additional pathogen (not reported by culture) in eight samples: K. pneumoniae in S5, $P$. aeruginosa in S7, M. catarrhalis in S14 and S39, S. pneumoniae in S8 and S15, S. aureus in S29 and S. pyogenes in S27 (Table 2). Up to two potentially pathogenic bacteria were also observed in seven samples reported as NRF/no significant growth (NSG) by routine microbiology i.e. H. influenzae and S. pneumoniae in S10 and S21; S. pneumoniae in S11 and S28; M. catarrhalis and H. influenzae in S12; H. influenzae in S31 and E. coli in S32. Only one pathogenic organism reported by routine microbiology was not detected using the optimised method i.e. S9. This was reported as a mixed infection with $P$. aeruginosa and $E$. 
coli, whereas only E. coli was detected by metagenomics. There were three other mixed infections reported by routine microbiology, S27, S38 and S41, and both organisms were detected in all three samples using the optimised method.

Confirmatory qPCR was used to establish the presence or absence of the missed/additional pathogens detected by metagenomics in 16 samples ( 1 sample with a missed pathogen, 15 samples with additional pathogen/s; total of 19 pathogens) and in matched controls i.e. an equal number of samples with no evidence of the pathogen by culture or metagenomics (Supplementary Table 5). This analysis was performed on DNA extracted from samples that did not undergo the depletion process, to rule out depletion as a potential cause of missed/additional pathogen detection. The majority of additional pathogens detected by metagenomics $(12 / 19)$ were confirmed by qPCR, which increased the specificity of the optimised method to $50 \%(95 \% \mathrm{Cl}, 21.09-78.91 \%$ - not counting additional organisms in culture-positive samples as false positives ( $n=2$, S5 positive for $K$. pneumoniae, likely k-mer mis-classification of $K$. oxytoca. $S 41$ positive for $E$. coli, likely laboratory/kit contamination)). qPCR was negative for $P$. aeruginosa (S9) increasing the sensitivity to $100 \%(95 \% \mathrm{Cl}$, 88.06-100\%).

Species-specific gene analysis was performed on all samples positive for pathobionts (potentially pathogenic organisms which may reside as commensals in the lung), i.e. $H$. influenzae and S. pneumoniae, which can have closely related non-pathogenic species present in the lungs (18 samples containing 20 pathobionts). This confirmatory analysis was used to identify k-mer mis-classification of commensal reads as pathogen reads by WIMP. Samples containing $>1 \mathrm{H}$. influenzae (siaT) or S. pneumoniae (ply) specific gene alignments were considered positive for that organism. The pathobiont-specific gene analysis confirmed the absence of $H$. influenzae/S. pneumoniae in $5 / 18$ samples (also negative by qPCR - see previous paragraph) and resulted in metagenomics test sensitivity of $100 \%(95 \% \mathrm{Cl}, 88.06-$ 
$100 \%)$ and specificity of $100 \%(95 \% \mathrm{Cl}, 73.54-100 \%)$ compared to the culture+qPCR gold standard (Supplementary Table 6).

\section{Antibiotic resistance}

The samples tested using the optimised method had little antibiotic resistance, based upon routine testing (Supplementary Table 7). Across the 33 cultivated organisms, just 43 instances of resistance and intermediate resistance were recorded (Supplementary Table 7), with some of these likely reflecting single underlying mechanisms. Sequencing identified 183 resistance genes across the 41 specimens (with multiple inclusions when ARMA identified multiple variants of e.g. b/aтем).

Among the 183 resistance genes, 26 were inherent to the species cultivated (e.g. oqxA/B for K. pneumoniae or blaoxA-50 in P. aeruginosa), leaving 157, of which 24 matched the phenotype seen (Table 3). These comprised of mecA in both MRSA (S16 and S40), sul1 and dfrA12 or dfrA17 in both co-trimoxazole-resistant E. coli (S1 and S9), aac(3')-Ila (and IIc) in a tobramycin-resistant E. coli (S9) and a total of 13 blaTEM variants spread recorded across two amoxicillin-resistant $E$. coli (S1 and S35 and two amoxicillin-resistant $H$. influenzae (S18 and S36). A caveat regarding this is that although ARMA flagged multiple blatem genes, it did not flag bla TEM-1, which was the likeliest variant, given (i) that it is considerably the most prevalent type and (ii) that the isolates remained susceptible to oxyimino- cephalosporins whereas many of the variants flagged should encode extendedspectrum variants. Depending on their strength of expression blaтем or blaoxy may have explained non-susceptibility to penicillin/ $\beta$-lactamase inhibitor combinations in Enterobacteriales (4/183 genes), but expression is not quantified by ARMA. A blaTEM4 gene (1/183) was also found in a ceftazidime- and piperacillin/tazobactam- resistant $P$. aeruginosa (S37); this could explain the phenotype but is unlikely in this species, where $\beta$-lactam resistance most often reflects up-regulation of chromosomal ampC or efflux. There were 
14/183 genes where any associated resistance could not be confirmed because no relevant drug(s) was tested by the clinical laboratory e.g. tet genes were identified in several samples (S2, S8, S9, S16, S30, S35, S38 and S39) but tetracycline was not tested against the isolates cultured. Sixteen genes detected by ARMA did not match the phenotype of isolates cultured, which remained susceptible to relevant antibiotics, and 42 genes were unlikely to be from species grown by the laboratory. Finally, multiple genes $(56 / 183)$ likely originated from the normal flora: thus tet(M) and blaTEM-4, each was found in 8/12 NRF/NSG specimens whilst $m e f A$ and $m e /$ were each found in $9 / 12$, as well as in many where the isolates grown were unlikely to have hosted these genes.

There were nine samples where phenotypic resistances remained unexplained by resistance genes found by ARMA. This included two amoxicillin-resistant M. catarrhalis (S8 and S26), where the BRO $\beta$-lactamase genes were likely to be responsible but were not represented in the ARMA database. The remaining seven samples included ampicillin- and co-trimoxazoleresistant $H$. influenzae (S7, S18, S36, S39 and S41), trimethoprim-, ciprofloxacingentamicin- and fusidic acid- resistant $S$. aureus (S16) and a K. pneumoniae (S2) resistant to both co-amoxiclav and piperacillin/tazobactam but lacking any acquired $\beta$-lactamase gene.

The specificity and sensitivity of the developed method for resistance gene detection was not determined as this would have required isolating and sequencing all bacteria (pathogens and commensals) present - a prohibitive task.

\section{Reference-based genome assembly}

Two samples containing antibiotic resistant bacteria were chosen as examples to generate reference-based genome assemblies directly from the metagenomic data. This analysis was performed to illustrate that whole pathogen genomes can be generated directly from 
respiratory samples for public health and infection control applications. Assemblies were generated for an MRSA (S16) and an E. coli resistant to amoxicillin, co-amoxiclav and cotrimoxazole (S1). The results were compared with those for undepleted controls after two and 48 hours of sequencing. Within the first two hours of sequencing the human DNA depleted MRSA sample had 47.9x genome coverage with an assembly of 28 contigs (GCA_900660255: longest contig $=478718$ and N50=400kbp). Genome coverage increased to $228.7 x$ after $48 \mathrm{hrs}$ of sequencing, with a final assembly consisting of 22 contigs (GCA_900660245: longest contig $=481 \mathrm{kbp}$ and N50=403kbp). In contrast, the undepleted MRSA sample had an assembly of 69 contigs with 3.9x coverage (GCA_900660235: longest contig $=47 \mathrm{kbp}$ and $\mathrm{N} 50=146 \mathrm{kbp})$ after $2 \mathrm{hrs}$ and 33 contigs $(17.5 \mathrm{x}$ coverage $)$ after 48 hours (GCA_900660205: longest contig $=416 \mathrm{kbp}$ and N50=263kbp) (Figure 2a).

For the sample positive for resistant $E$. coli there was $33.5 \mathrm{x}$ genome coverage within two hours for the depleted sample, with an assembly of 83 contigs (GCA_900660265: longest contig $=437 \mathrm{kbp}$ and N50=165kbp). Genome coverage increased to $165.7 x$ after 48 hrs with the final E. coli assembly having 72 contigs (GCA_900660275: longest contig $=474 \mathrm{kbp}$ and $\mathrm{N} 50=178 \mathrm{kbp})$. The undepleted sample only produced $0.2 \mathrm{x}$ coverage after $2 \mathrm{hrs}$, which increased to $1.1 \mathrm{x}$ after $48 \mathrm{hrs}$ of sequencing (Figure $2 \mathrm{~b}$ ).

\section{Time-point analysis}

Using the same sample set as for genome assembly, data from the first two hours of sequencing were compared over time for depleted samples and undepleted controls to highlight the importance of host depletion for turnaround-time to result. Within 5 min of sequencing the depleted MRSA sample (S16) had 1.6x genome coverage compared with $0.2 x$ coverage for the undepleted control (Figure $2 \mathrm{c}$ ). The mecA gene was not detected in the undepleted sample after 5 min whereas two mecA gene alignments were detected in the depleted sample by the same time point (Figure 2d). 
The depleted E. coli sample (S1) had 5.7x genome coverage within 20 min of sequencing compared to $0.06 x$ for the undepleted control (Figure 2e). This E. coli was resistant to amoxicillin (bla TEM gene), co-amoxiclav (possibly owing to bla TEM $_{\text {if }}$ strongly expressed) and co-trimoxazole (sul1 and dfrA17 genes). The bla TEM and dfrA17 genes were not detected in the undepleted sample within two hours of sequencing and only one alignment was detected for sul1. Conversely, all three resistance genes were detected within 20 min of sequencing in the depleted sample and, after two hours, 47 bla TEM $_{1}, 37$ sulf1 and 21 dfrA 17 alignments were detected (Figure 2f).

\section{Discussion}

Culture-based diagnostics and susceptibility testing, in use for 70 years ${ }^{35}$, have limitations as guides for the appropriate clinical management of acute infections, mainly because of their slow sample-to-result turnaround. Rapid, accurate diagnostics would enable treatment with appropriate antibiotics and improve health outcomes and antimicrobial stewardship alike. We developed a method to prepare respiratory samples for metagenomics sequencing and incorporated it into a nanopore metagenomic sequencing protocol for bacterial pathogen and antibiotic resistance gene identification in LRIs within 6h of sample receipt.

Our metagenomics workflow for respiratory samples includes host DNA depletion, microbial DNA extraction, library preparation, MinION sequencing and real-time data analysis. A pipeline was developed (pilot method) and tested on 40 respiratory samples. We then optimised our method by shortening the depletion protocol, introducing bead-beating for improved microbial lysis, and reducing the library preparation time. Mock community analysis demonstrated that the saponin based human DNA depletion method didn't inadvertently remove DNA from common respiratory pathogens, except for $S$. pneumoniae (mean 5.8 fold loss - Supplementary Table 3). It is possible that S. pneumoniae cells may have lysed during the host DNA depletion process ${ }^{36}$ or might have lysed when grown to stationary phase for our mock community experiments. S. pneumoniae was correctly identified by metagenomics in five of six culture-positive patients, but it may have been 
underrepresented in these samples. The time from sample collection to bacterial DNA extraction may be crucial for accurate detection of $S$. pneumoniae.

The LoD of our optimised method $\left(10^{3}-10^{5} \mathrm{cfu} / \mathrm{ml}\right)$ is within the range of culturebased clinical thresholds applied to respiratory samples. Our optimized method was $96.6 \%$ sensitive and $41.7 \%$ specific compared to culture. Discordant results were investigated using pathogen specific probe-based qPCR assays (Supplementary Table 5) which increased sensitivity (100\%) and specificity (50\%). Five of seven remaining discordant samples were positive for pathobionts, specifically $H$. influenzae and/or S. pneumoniae, by metagenomics. These false positive detections can be caused by misclassification of reads by WIMP, as $k$ mer based read classification can be unreliable at the species level, particularly where species in a genus are highly related or share genes ${ }^{37,38}$. To overcome this problem we introduced post-hoc pathobiont-specific gene analysis for all $H$. influenzae and/or $S$. pneumoniae positive samples ( $n=20$ pathobionts in 18 samples). This analysis confirmed that the false positive results $(n=5)$ were caused by $k$-mer misclassification and resulted in metagenomics test sensitivity and specificity of $100 \%$ compared to culture+qPCR gold standard. This issue highlights the need for new methods to accurately identify bacterial species from metagenomic data ${ }^{39}$.

To maximise the impact on patient management, identification of clinically relevant antibiotic resistance genes as well as the infecting pathogen/s is necessary. In this regard the present pipeline has potential but requires refinement. Both MRSA cases were identified by the presence of $m e c A$, with no false positives for this gene. Co-trimoxazole resistance in Enterobacteriaceae was accurately identified with detection of sul and dfr genes and these were not found in $H$. influenzae, for which resistance is largely mutational ${ }^{40,41}$. However, genes such as tet(M), mel, mefA and blaтеM were found in all samples where no pathogen was grown, suggesting presence in the normal or colonising respiratory flora. To overcome this issue, it will be necessary to associate resistance genes to particular organisms. This can be done by examining flanking sequences ${ }^{42-45}$ in the c. $3 \mathrm{~kb}$ nanopore reads in cases where a gene is chromosomally inserted (not plasmid-borne resistance genes), as is usual 
for transposon borne tet( $M)$ and mefA in streptococci ${ }^{46-48}$, including $S$. pneumoniae (Supplementary Figure 1).

Clinical metagenomics data could also be used to assemble pathogen genomes for reference laboratory typing. The quality/depth of the metagenomic data generated by our method could enable monitoring of emergence and patient-to-patient spread of pathogens and antimicrobial resistance directly from clinical samples in real-time ${ }^{49,50}$. Using PCR for respiratory infection diagnosis must be coupled with microbiological culture, otherwise the link to phenotype is lost, whereas clinical metagenomics could replace routine culture entirely. As viruses are an important cause of LRIs, they can be tested for using PCR, as is current routine practice, or our pipeline could be modified to detect viral nucleic acid by processing the supernatant fraction after centrifugation of the respiratory sample (Figure 1, step 1).

In conclusion, we report the first rapid clinical metagenomics pipeline for the characterization of bacterial LRIs. Pathogens and antibiotic resistance genes can be identified in six hours. With additional sequencing time (up to $48 \mathrm{hrs}$ ), it provides sufficient data for public health and infection control applications. Our protocol is being evaluated in a clinical trial (INHALE - http://www.ucl.ac.uk/news/news-articles/1115/181115-moleculardiagnosis-pneumonia) to evaluate the rapid diagnosis of hospital-acquired and ventilatorassociated pneumonia in comparison with culture and multiplex-PCR.

\section{Acknowledgements}

This paper presents independent research funded by the National Institute for Health Research (NIHR) under its Programme Grants for Applied Research Programme (Reference Number RP-PG-0514-20018, JOG, HR), the UK Antimicrobial Resistance Cross Council Initiative (MR/N013956/1, JOG, GLK), Rosetrees Trust (A749, JOG), the University of East Anglia (JOG, TC), Oxford Nanopore Technologies (JOG, TC, AA, DJT), Quadram Institute Bioscience BBSRC Strategic Programme: Microbes in the Food Chain (project number BB/R012504/1, JOG, GLK) and BBSRC grants (BB/N023196/1 and BB/CSP17270/1, RML). 
Part of the bioinformatics analysis was run on CLIMB-computing servers, an infrastructure supported by a grant from the UK Medical Research Council (MR/L015080/1).

\section{Author Contributions}

The study was devised by JOG, JW, DJT. Laboratory work and data analysis was performed by TC, GLK, AA, HR, RB, DML, RML, JOG. Clinical samples were collected and analysed by CJ, SG, DR. All authors contributed to writing and reviewing the manuscript.

\section{Competing Financial Interests Statement}

JOG, RML, GLK and TC received financial support for attending ONT and other conferences and/or an honorarium for speaking at ONT headquarters. JOG, AA and TC received funding and consumable support from ONT for PhD studentships. DJT is a full-time employee and share-option holder of Oxford Nanopore Technologies Ltd. RML and JOG received free flowcells as part of the MAP and MARC programmes.

\section{References}

1. NICE. in NICE clinical guideline 69 (Centre for Clinical Practice 2008 ).

2. Chalmers, J. et al. Community-acquired pneumonia in the United Kingdom: a call to action. Pneumonia 9, 15 (2017).

3. Enne, V.I., Personne, Y., Grgic, L., Gant, V. \& Zumla, A. Aetiology of hospitalacquired pneumonia and trends in antimicrobial resistance. Current Opinion in Pulmonary Medicine 20, 252-258 (2014).

4. $\quad$ Carroll, K.C. Laboratory Diagnosis of Lower Respiratory Tract Infections:

Controversy and Conundrums. Journal of Clinical Microbiology 40, 3115-3120 (2002).

5. Kollef, M.H. Microbiological Diagnosis of Ventilator-associated Pneumonia. American Journal of Respiratory and Critical Care Medicine 173, 1182-1184 (2006).

6. Moran, G.J., Rothman, R.E. \& Volturo, G.A. Emergency management of communityacquired bacterial pneumonia: What is new since the 2007 Infectious Diseases Society of America/American Thoracic Society guidelines. American Journal of Emergency Medicine 31, 602-612 (2013).

7. Garcin, F. et al. Non-adherence to guidelines: an avoidable cause of failure of empirical antimicrobial therapy in the presence of difficult-to-treat bacteria. Intensive Care Medicine 36, 75-82 (2010).

8. Lim, W.S. et al. BTS guidelines for the management of community acquired pneumonia in adults: update 2009. Thorax 64, iii1 (2009).

9. Burnham, C.A. \& Carroll, K.C. Diagnosis of Clostridium difficile infection: an ongoing conundrum for clinicians and for clinical laboratories. Clinical microbiology reviews 26, 604630 (2013). 
10. Lees, E.A., Miyajima, F., Pirmohamed, M. \& Carrol, E.D. The role of Clostridium difficile in the paediatric and neonatal gut - a narrative review. European Journal of Clinical Microbiology \& Infectious Diseases 35, 1047-1057 (2016).

11. Cookson, W.O.C.M., Cox, M.J. \& Moffatt, M.F. New opportunities for managing acute and chronic lung infections. Nature Reviews Microbiology 16, 111 (2017).

12. Davies, S.C. Chapter 1 Chief Medical Officer's summary. Annual Report of the Chief Medical Officer (2016).

13. Goverment, H. (2019).

14. O'Neill, J. Tackling drug-resistant infections globally: final report and recommendations. 84 (2016).

15. Fukumoto, H., Sato, Y., Hasegawa, H., Saeki, H. \& Katano, H. Development of a new real-time PCR system for simultaneous detection of bacteria and fungi in pathological samples. 8, 15479-15488 (2015).

16. Hassibi, A. et al. Multiplexed identification, quantification and genotyping of infectious agents using a semiconductor biochip. Nature Biotechnology (2018).

17. Kais, M., Spindler, C., Kalin, M., Örtqvist, A. \& Giske, C.G. Quantitative detection of Streptococcus pneumoniae, Haemophilus influenzae, and Moraxella catarrhalis in lower respiratory tract samples by real-time PCR. Diagnostic Microbiology and Infectious Disease 55, 169-178 (2006).

18. Kodani, M. et al. Application of TaqMan Low-Density Arrays for Simultaneous Detection of Multiple Respiratory Pathogens. Journal of Clinical Microbiology 49, 2175-2182 (2011).

19. Hayon, J.A.N. et al. Role of Serial Routine Microbiologic Culture Results in the Initial Management of Ventilator-associated Pneumonia. American Journal of Respiratory and Critical Care Medicine 165, 41-46 (2002).

20. Buchan, B.W. \& Ledeboer, N.A. Emerging Technologies for the Clinical Microbiology Laboratory. Clinical microbiology reviews 27, 783 (2014).

21. Huang, T.-D. et al. Analytical validation of a novel high multiplexing real-time PCR array for the identification of key pathogens causative of bacterial ventilator-associated pneumonia and their associated resistance genes. Journal of Antimicrobial Chemotherapy 68, 340-347 (2012).

22. Chiu, C.Y. \& Miller, S.A. Clinical metagenomics. Nature Reviews Genetics (2019).

23. Loman, N.J. et al. Performance comparison of benchtop high-throughput sequencing platforms. Nature Biotechnology 30, 434 (2012).

24. Strauch, B. et al. LiveKraken--real-time metagenomic classification of illumina data. Bioinformatics 34, 3750-3752 (2018).

25. Faria, N.R. et al. Establishment and cryptic transmission of Zika virus in Brazil and the Americas. Nature 546, 406 (2017).

26. Quick, J. et al. Real-time, portable genome sequencing for Ebola surveillance. Nature 530, 228 (2016).

27. Greninger, A.L. et al. Rapid metagenomic identification of viral pathogens in clinical samples by real-time nanopore sequencing analysis. Genome Medicine 7, 99 (2015).

28. Schmidt, K. et al. Identification of bacterial pathogens and antimicrobial resistance directly from clinical urines by nanopore-based metagenomic sequencing. Journal of Antimicrobial Chemotherapy 72, 104-114 (2017).

29. Pendleton, K.M. et al. Rapid Pathogen Identification in Bacterial Pneumonia Using Real-Time Metagenomics. American Journal of Respiratory and Critical Care Medicine 196, 1610-1612 (2017).

30. Feehery, G.R. et al. A Method for Selectively Enriching Microbial DNA from Contaminating Vertebrate Host DNA. PLOS ONE 8, e76096 (2013).

31. Hasan, M.R. et al. Depletion of Human DNA in Spiked Clinical Specimens for Improvement of Sensitivity of Pathogen Detection by Next-Generation Sequencing. Journal of Clinical Microbiology 54, 919-927 (2016).

32. Marotz, C.A. et al. Improving saliva shotgun metagenomics by chemical host DNA depletion. Microbiome 6, 42 (2018). 
33. Zelenin, S. et al. Microfluidic-based isolation of bacteria from whole blood for sepsis diagnostics. Biotechnology Letters 37, 825-830 (2015).

34. Couto, N. et al. Critical steps in clinical shotgun metagenomics for the concomitant detection and typing of microbial pathogens. Scientific Reports 8, 13767 (2018).

35. McIntosh, J. Emergency Pathology Service. The Lancet 247, 669-670 (1946).

36. Martner, A., Dahlgren, C., Paton, J.C. \& Wold, A.E. Pneumolysin Released during Streptococcus pneumoniae Autolysis Is a Potent Activator of Intracellular Oxygen Radical Production in Neutrophils. Infection and Immunity 76, 4079-4087 (2008).

37. Chen, J.H.K. et al. Use of MALDI Biotyper plus ClinProTools mass spectra analysis for correct identification of Streptococcus pneumoniae and Streptococcus mitis. Journal of Clinical Pathology (2015).

38. Kutlu, S.S., Sacar, S., Cevahir, N. \& Turgut, H. Community-acquired Streptococcus mitis meningitis: a case report. International Journal of Infectious Diseases 12, e107-e109 (2008).

39. Langelier, C. et al. Integrating host response and unbiased microbe detection for lower respiratory tract infection diagnosis in critically ill adults. Proceedings of the National Academy of Sciences 115, E12353 (2018).

40. Eliopoulos, G.M. \& Huovinen, P. Resistance to Trimethoprim-Sulfamethoxazole. Clinical Infectious Diseases 32, 1608-1614 (2001).

41. Enne, V.I., King, A., Livermore, D.M. \& Hall, L.M.C. Sulfonamide Resistance in Haemophilus influenzae Mediated by Acquisition of sul2 or a Short Insertion in Chromosomal folP. Antimicrobial Agents and Chemotherapy 46, 1934-1939 (2002).

42. Ashton, P.M. et al. MinION nanopore sequencing identifies the position and structure of a bacterial antibiotic resistance island. Nature Biotechnology 33, 296 (2014).

43. Orlek, A. et al. Plasmid Classification in an Era of Whole-Genome Sequencing: Application in Studies of Antibiotic Resistance Epidemiology. Frontiers in Microbiology 8 (2017).

44. Xia, Y. et al. MinION Nanopore Sequencing Enables Correlation between Resistome Phenotype and Genotype of Coliform Bacteria in Municipal Sewage. Frontiers in Microbiology 8 (2017).

45. Leggett, R.M. et al. Rapid MinION metagenomic profiling of the preterm infant gut microbiota to aid in pathogen diagnostics. bioRxiv (2017).

46. Roberts, A.P. \& Mullany, P. Tn916-like genetic elements: a diverse group of modular mobile elements conferring antibiotic resistance. FEMS Microbiology Reviews 35, 856-871 (2011).

47. Santoro, F., Vianna, M.E. \& Roberts, A.P. Variation on a theme; an overview of the Tn916/Tn1545 family of mobile genetic elements in the oral and nasopharyngeal streptococci. Frontiers in Microbiology 5 (2014).

48. Tantivitayakul, P., Lapirattanakul, J., Vichayanrat, T. \& Muadchiengka, T. Antibiotic Resistance Patterns and Related Mobile Genetic Elements of Pneumococci and $\beta$-Hemolytic Streptococci in Thai Healthy Children. Indian Journal of Microbiology 56, 417-425 (2016).

49. Deurenberg, R.H. et al. Application of next generation sequencing in clinical microbiology and infection prevention. Journal of Biotechnology 243, 16-24 (2017).

50. Greninger, A.L. et al. Rapid Metagenomic Next-Generation Sequencing during an Investigation of Hospital-Acquired Human Parainfluenza Virus 3 Infections. Journal of Clinical Microbiology 55, 177-182 (2017). 


\section{Figure legends}

Figure 1: Schematic representation of the metagenomic pipeline with a turnaround time of approx. six hours (optimised) and approx. eight hours (pilot) from sample collection to sample result.

Figure 2: Bacterial genome assembly, genome coverage and antibiotic gene detection with depleted versus undepleted samples.

A: MRSA after 48 hours of sequencing.

B: E. coli after 48 hours of sequencing.

C: MRSA genome coverage of depleted versus undepleted during two hours of sequencing*.

D: $m e c A$ gene alignment of depleted versus undepleted during two hours of sequencing*.

$\mathrm{E}:$ E. coli genome coverage of depleted versus undepleted during two hours of sequencing*.

F: blaтем, sul1 and dfrA17 gene alignment of depleted versus undepleted during two hours of sequencing*.

${ }^{*}$ Three independent clinical samples were analysed (an example of a Gram positive and a Gram negative are respresented). 
Table1: Pilot metagenomic pipeline output compared to routine microbiology culture results.

\begin{tabular}{|c|c|c|}
\hline Sample & $\begin{array}{c}\text { Pathogen cultured by } \\
\text { microbiology }\end{array}$ & $\begin{array}{l}\text { Pathogen identified from } \\
\text { metagenomic pipeline }\end{array}$ \\
\hline P1 & Coliform* & P. mirabilis \\
\hline P2 & NRF & None \\
\hline \multirow[t]{2}{*}{ P3 } & \multirow{2}{*}{$\begin{array}{l}P . \text { aeruginosa } \\
\text { S. pneumoniae }\end{array}$} & $P$. aeruginosa \\
\hline & & \\
\hline P4 & NRF & None \\
\hline P5 & Coliform* & E. coli \\
\hline P6 & Coliform* ${ }^{*}$ & K. pneumoniae \\
\hline P7 & Coliform* & S. marcescens \\
\hline \multirow[t]{2}{*}{ P8 } & \multirow[t]{2}{*}{ H. influenzae } & H. influenzae \\
\hline & & M. catarrhalis \\
\hline P9 & H. influenzae & H. influenzae \\
\hline P10 & MRSA & MRSA \\
\hline P11 & Coliform* & E. coli \\
\hline P12 & K. pneumoniae & K. pneumoniae \\
\hline P13 & E. coli & E. coli \\
\hline \multirow[t]{3}{*}{ P14 } & \multirow{3}{*}{$\begin{array}{c}\text { K. pneumoniae } \\
\text { E. cloacae }\end{array}$} & K. pneumoniae \\
\hline & & E. cloacae \\
\hline & & E. coli \\
\hline P15 & S. aureus & S. aureus \\
\hline P16 & S. aureus & S. aureus \\
\hline P17 & NRF & None \\
\hline P18 & NRF & None \\
\hline P19 & NRF & None \\
\hline P20 & NRF & None \\
\hline P21 & K. pneumoniae & K. pneumoniae \\
\hline
\end{tabular}

\begin{tabular}{|c|c|c|}
\hline Sample & $\begin{array}{l}\text { Pathogen cultured } \\
\text { by microbiology }\end{array}$ & $\begin{array}{l}\text { Pathogen identified from } \\
\text { metagenomic pipeline }\end{array}$ \\
\hline \multirow[t]{2}{*}{ P22 } & \multirow[t]{2}{*}{$P$. aeruginosa } & $P$. aeruginosa \\
\hline & & H. influenzae \\
\hline P23 & S. aureus & S. aureus \\
\hline P24 & H. influenzae & H. influenzae \\
\hline P25 & H. influenzae & H. influenzae \\
\hline P26 & M. catarrhalis & M. catarrhalis \\
\hline P27 & H. influenzae & H. influenzae \\
\hline \multirow[t]{2}{*}{ P28 } & \multirow{2}{*}{$\begin{array}{c}\text { S. pneumoniae } \\
\text { H. influenzae }\end{array}$} & S. pneumoniae \\
\hline & & H. influenzae \\
\hline \multirow[t]{3}{*}{ P29 } & \multirow[t]{3}{*}{ H. influenzae } & H. influenzae \\
\hline & & K. pneumoniae \\
\hline & & M. catarrhalis \\
\hline \multirow[t]{2}{*}{ P30 } & \multirow[t]{2}{*}{ S. pneumoniae } & S. pneumoniae \\
\hline & & H. influenzae \\
\hline \multirow[t]{2}{*}{ P31 } & \multirow{2}{*}{$\begin{array}{l}\text { E. aerogenes } \\
\text { S. aureus }\end{array}$} & E. aerogenes \\
\hline & & S. aureus \\
\hline P32 & $P$. aeruginosa & $P$. aeruginosa \\
\hline P33 & S. pneumoniae & S. pneumoniae \\
\hline P34 & S. aureus & \\
\hline P35 & H. influenzae & H. influenzae \\
\hline P36 & S. pneumoniae & S. pneumoniae \\
\hline \multirow[t]{2}{*}{ P37 } & \multirow{2}{*}{$\begin{array}{l}\text { H. influenzae } \\
\text { Coliform* }\end{array}$} & \\
\hline & & K. oxytoca \\
\hline P38 & MRSA & MRSA \\
\hline P39 & S. aureus & S. aureus \\
\hline \multirow[t]{2}{*}{ P40 } & \multirow{2}{*}{$\begin{array}{l}\text { H. influenzae } \\
\text { S. pneumoniae }\end{array}$} & H. influenzae \\
\hline & & S. pneumoniae \\
\hline
\end{tabular}


Table 2. Human and bacterial DNA qPCR results for sputum samples infected by Gram-negative and Gram-positive bacteria with and without host nucleic acid depletion

\begin{tabular}{|c|c|c|c|c|c|c|c|c|}
\hline Sample & $\begin{array}{c}\text { Sample } \\
\text { type }\end{array}$ & $\begin{array}{c}\text { Organism cultured } \\
\text { by microbiology }\end{array}$ & $\begin{array}{c}\text { Organism identified } \\
\text { from metagenomic } \\
\text { pipeline }\end{array}$ & $\begin{array}{c}\text { Sample } \\
\text { treatment }\end{array}$ & $\begin{array}{c}\text { Human } \\
\text { qPCR } \\
\text { assay }(\mathrm{Cq})\end{array}$ & $\begin{array}{l}\text { Human } \\
\text { DNA } \\
\text { depletion } \\
(\Delta \mathrm{Cq})\end{array}$ & $\begin{array}{c}\text { 16S rRNA } \\
\text { gene V3-V4 } \\
\text { fragment } \\
\text { qPCR assay } \\
\text { (Cq) }\end{array}$ & $\begin{array}{c}\text { Bacterial } \\
\text { gain/loss } \\
\text { to } \\
\text { standard } \\
\text { depletion } \\
(\Delta \mathrm{Cq}) \\
\end{array}$ \\
\hline \multirow[t]{2}{*}{ S1 } & \multirow[t]{2}{*}{ ETA } & \multirow[t]{2}{*}{ E. coli } & \multirow[t]{2}{*}{ E. coli } & Undepleted & 22.62 & \multirow{2}{*}{$\begin{array}{l}12.38 \\
\left(\sim 10^{4}\right) \\
\end{array}$} & 15.60 & \multirow[t]{2}{*}{0.13} \\
\hline & & & & Depleted & 35.00 & & 15.73 & \\
\hline \multirow[t]{2}{*}{ S2 } & \multirow[t]{2}{*}{ Sputum } & \multirow[t]{2}{*}{ K. pneumoniae } & \multirow[t]{2}{*}{ K. pneumoniae } & Undepleted & 23.73 & \multirow{2}{*}{$\begin{array}{c}9.99 \\
\left(\sim 10^{3}\right)\end{array}$} & 15.63 & \multirow[t]{2}{*}{0.02} \\
\hline & & & & Depleted & 33.71 & & 15.65 & \\
\hline \multirow[t]{2}{*}{ S3 } & \multirow[t]{2}{*}{ Sputum } & \multirow[t]{2}{*}{$P$. aeruginosa } & \multirow[t]{2}{*}{$P$. aeruginosa } & Undepleted & 23.05 & \multirow{2}{*}{$\begin{array}{c}9.29 \\
\left(\sim 10^{3}\right)\end{array}$} & 15.46 & \multirow[t]{2}{*}{1.48} \\
\hline & & & & Depleted & 32.34 & & 13.98 & \\
\hline \multirow[t]{2}{*}{ S4 } & \multirow[t]{2}{*}{ Sputum } & \multirow[t]{2}{*}{ S. marcescens } & \multirow[t]{2}{*}{ S. marcescens } & Undepleted & 26.34 & \multirow{2}{*}{$\begin{array}{c}9.93 \\
\left(\sim 10^{3}\right) \\
\end{array}$} & 16.96 & \multirow[t]{2}{*}{0.52} \\
\hline & & & & Depleted & 36.27 & & 17.48 & \\
\hline \multirow{2}{*}{ S5 } & \multirow{2}{*}{ Sputum } & \multirow{2}{*}{ K. oxytoca } & K. oxytoca & Undepleted & 22.96 & \multirow{2}{*}{$\begin{array}{c}8.58 \\
\left(\sim 10^{3}\right)\end{array}$} & 12.67 & \multirow[t]{2}{*}{0.64} \\
\hline & & & K. pneumoniae & Depleted & 31.54 & & 12.03 & \\
\hline \multirow[t]{2}{*}{ S6 } & \multirow[t]{2}{*}{ Sputum } & \multirow[t]{2}{*}{ S. aureus } & S. aureus & Undepleted & 22.31 & 9.41 & 19.11 & 1.57 \\
\hline & & & & Depleted & 31.72 & $\left(\sim 10^{3}\right)$ & 17.54 & \\
\hline S7 & Sputum & H. influenzae & H. influenzae & Undepleted & 25.47 & 9.53 & 21.44 & 0.43 \\
\hline & & & $P$. aeruginosa & Depleted & 35.00 & $\left(\sim 10^{3}\right)$ & 21.87 & \\
\hline S8 & Sputum & M. catarrhalis & M. catarrhalis & Undepleted & 22.72 & 9.17 & 16.9 & 0.66 \\
\hline & & & S. pneumoniae & Depleted & 31.89 & $\left(\sim 10^{3}\right)$ & 17.56 & \\
\hline S9 & Sputum & $P$. aeruginosa & & Undepleted & 23.89 & 11.11 & 19.58 & 3.26 \\
\hline & & \& E. coli & E. coli & Depleted & 35 & $\left(\sim 10^{4}\right)$ & 22.84 & \\
\hline S10 & Sputum & NSG & H. influenzae & Undepleted & 23.46 & 8.6 & 14.12 & 2.39 \\
\hline & & & S. pneumoniae & Depleted & 32.06 & $\left(\sim 10^{3}\right)$ & 16.51 & \\
\hline S11 & Sputum & NRF & S. pneumoniae & Undepleted & 25.77 & 9.23 & 17.96 & 1.92 \\
\hline & & & & Depleted & 35.00 & $\left(\sim 10^{3}\right)$ & 19.88 & \\
\hline S12 & Sputum & NRF & H. influenzae & Undepleted & 22.5 & 8.92 & 17.61 & 0.05 \\
\hline & & & M. catarrhalis & Depleted & 31.42 & $\left(\sim 10^{3}\right)$ & 17.56 & \\
\hline
\end{tabular}




\begin{tabular}{|c|c|c|c|c|c|c|c|c|}
\hline \multirow[t]{2}{*}{ S13 } & \multirow[t]{2}{*}{ Sputum } & \multirow[t]{2}{*}{ S. marcescens } & \multirow[t]{2}{*}{ S. marcescens } & Undepleted & 22.48 & \multirow{2}{*}{$\begin{array}{c}7.11 \\
\left(\sim 10^{2}\right) \\
\end{array}$} & 12.77 & \multirow[t]{2}{*}{0.79} \\
\hline & & & & Depleted & 29.59 & & 11.98 & \\
\hline \multirow{2}{*}{ S14 } & \multirow{2}{*}{ Sputum } & \multirow{2}{*}{ S. aureus } & S. aureus & Undepleted & 23.17 & \multirow{2}{*}{$\begin{array}{c}7.68 \\
\left(\sim 10^{2}\right)\end{array}$} & 13.83 & \multirow[t]{2}{*}{0.96} \\
\hline & & & M. catarrhalis & Depleted & 30.85 & & 14.79 & \\
\hline \multirow[t]{2}{*}{ S15 } & \multirow[t]{2}{*}{ Sputum } & \multirow[t]{2}{*}{ S. aureus } & S. aureus & Undepleted & 22.66 & \multirow{2}{*}{$\begin{array}{c}8.47 \\
\left(\sim 10^{3}\right)\end{array}$} & 18.73 & \multirow[t]{2}{*}{0.08} \\
\hline & & & S. pneumoniae & Depleted & 31.13 & & 18.65 & \\
\hline \multirow[t]{2}{*}{$\mathbf{S 1 6}$} & \multirow[t]{2}{*}{ Sputum } & \multirow[t]{2}{*}{ MRSA } & \multirow[t]{2}{*}{ MRSA } & Undepleted & 25.51 & \multirow{2}{*}{$\begin{array}{c}6.43 \\
\left(\sim 10^{2}\right)\end{array}$} & 15.32 & \multirow[t]{2}{*}{0.24} \\
\hline & & & & Depleted & 31.94 & & 15.56 & \\
\hline \multirow[t]{2}{*}{$\mathrm{S} 17$} & \multirow[t]{2}{*}{ Sputum } & \multirow[t]{2}{*}{ NRF } & \multirow[t]{2}{*}{ None } & Undepleted & 23.51 & \multirow{2}{*}{$\begin{array}{c}9.64 \\
\left(\sim 10^{3}\right)\end{array}$} & 19.55 & \multirow[t]{2}{*}{1.17} \\
\hline & & & & Depleted & 33.15 & & 20.72 & \\
\hline S18 & Sputum & H. influenzae & H. influenzae & Undepleted & 27.14 & 7.86 & 12.89 & 2.21 \\
\hline & & & & Depleted & 35.00 & $\left(\sim 10^{2}\right)$ & 15.10 & \\
\hline $\mathbf{S 1 9}$ & Sputum & NRF & None & Undepleted & 22.63 & 11.18 & 19.69 & 0.69 \\
\hline & & & & Depleted & 33.81 & $\left(\sim 10^{3}\right)$ & 19.00 & \\
\hline S20 & Sputum & H. influenzae & H. influenzae & Undepleted & 22.44 & 10.03 & 14.99 & 1.19 \\
\hline & & & & Depleted & 32.47 & $\left(\sim 10^{3}\right)$ & 16.18 & \\
\hline S21 & Sputum & NRF & H. influenzae & Undepleted & 24.58 & 10.42 & 16.60 & 0.82 \\
\hline & & & S. pneumoniae & Depleted & 35.00 & $\left(\sim 10^{3}\right)$ & 17.42 & \\
\hline S22 & Sputum & NRF & None & Undepleted & 22.71 & 9.22 & 14.62 & 0.39 \\
\hline & & & & Depleted & 31.93 & $\left(\sim 10^{3}\right)$ & 15.01 & \\
\hline S23 & Sputum & H. influenzae & H. influenzae & Undepleted & 24.82 & 10.18 & 16.80 & 1.84 \\
\hline & & & & Depleted & 35.00 & $\left(\sim 10^{3}\right)$ & 18.64 & \\
\hline S24 & Sputum & H. influenzae & H. influenzae & Undepleted & 22.24 & 10.17 & 15.70 & 1.63 \\
\hline & & & & Depleted & 32.41 & $\left(\sim 10^{3}\right)$ & 17.33 & \\
\hline S25 & Sputum & H. influenzae & H. influenzae & Undepleted & 25.52 & 6.26 & 16.59 & 2.67 \\
\hline & & & & Depleted & 31.79 & $\left(\sim 10^{2}\right)$ & 19.26 & \\
\hline S26 & Sputum & M. catarrhalis & M. catarrhalis & Undepleted & 23.47 & 11.53 & 19.26 & 0.74 \\
\hline & & & & Depleted & 35.00 & $\left(\sim 10^{4}\right)$ & 20.00 & \\
\hline S27 & Sputum & H. influenzae & H. influenzae & Undepleted & 32.74 & 2.26 & 23.19 & 7.92 \\
\hline & & \& S. aureus & S. aureus & Depleted & 35.00 & $(\sim 5)$ & 15.27 & \\
\hline & & & S. pyogenes & & & & & \\
\hline S28 & Sputum & NRF & S. pneumoniae & Undepleted & 24.46 & 10.54 & 22.28 & 2.80 \\
\hline & & & & Depleted & 35.00 & $\left(\sim 10^{3}\right)$ & 25.08 & \\
\hline S29 & Sputum & $P$. aeruginosa & $P$. aeruginosa & Undepleted & 24.05 & 5.11 & 19.81 & 2.04 \\
\hline
\end{tabular}




\begin{tabular}{|c|c|c|c|c|c|c|c|c|}
\hline & & & S. aureus & Depleted & 29.13 & $\left(\sim 10^{2}\right)$ & 17.77 & \\
\hline \multirow[t]{2}{*}{ S30 } & \multirow[t]{2}{*}{$\mathrm{BAL}$} & \multirow[t]{2}{*}{ P. aeruginosa } & \multirow[t]{2}{*}{ P. aeruginosa } & Undepleted & 29.93 & \multirow{2}{*}{$\begin{array}{l}5.07 \\
(\sim 33)\end{array}$} & 22.68 & \multirow[t]{2}{*}{0.00} \\
\hline & & & & Depleted & $>35.00$ & & 22.68 & \\
\hline \multirow[t]{2}{*}{ S31 } & \multirow[t]{2}{*}{ Sputum } & \multirow[t]{2}{*}{ NRF } & \multirow[t]{2}{*}{ H. influenzae } & Undepleted & 21.57 & \multirow{2}{*}{$\begin{array}{c}8.26 \\
\left(\sim 10^{3}\right)\end{array}$} & 19.79 & \multirow[t]{2}{*}{1.65} \\
\hline & & & & Depleted & 29.83 & & 21.44 & \\
\hline \multirow[t]{2}{*}{ S32 } & \multirow[t]{2}{*}{ Sputum } & \multirow[t]{2}{*}{ NSG } & \multirow[t]{2}{*}{ E. coli } & Undepleted & 25.56 & \multirow{2}{*}{$\begin{array}{c}8.68 \\
\left(\sim 10^{3}\right)\end{array}$} & 15.98 & \multirow[t]{2}{*}{0.47} \\
\hline & & & & Depleted & 34.24 & & 16.45 & \\
\hline \multirow[t]{2}{*}{ S33 } & \multirow[t]{2}{*}{ Sputum } & \multirow[t]{2}{*}{ NRF } & \multirow[t]{2}{*}{ None } & Undepleted & 21.73 & \multirow{2}{*}{$\begin{array}{c}10.04 \\
\left(\sim 10^{3}\right)\end{array}$} & 20.69 & \multirow[t]{2}{*}{0.81} \\
\hline & & & & Depleted & 31.77 & & 21.50 & \\
\hline \multirow[t]{2}{*}{ S34 } & \multirow[t]{2}{*}{ Sputum } & \multirow[t]{2}{*}{ NSG } & \multirow[t]{2}{*}{ None } & Undepleted & 25.17 & \multirow{2}{*}{$\begin{array}{c}5.40 \\
\left(\sim 10^{2}\right)\end{array}$} & 22.92 & \multirow[t]{2}{*}{0.01} \\
\hline & & & & Depleted & 30.57 & & 22.93 & \\
\hline \multirow[t]{2}{*}{ S35 } & \multirow[t]{2}{*}{ Sputum } & E. coli & E. coli & Undepleted & 21.11 & 5.18 & 16.49 & 0.58 \\
\hline & & & & Depleted & 26.29 & $\left(\sim 10^{2}\right)$ & 17.07 & \\
\hline S36 & Sputum & H. influenzae & H. influenzae & Undepleted & 22.58 & 9.70 & 16.51 & 2.00 \\
\hline & & & & Depleted & 32.28 & $\left(\sim 10^{3}\right)$ & 18.51 & \\
\hline S37 & Sputum & P. aeruginosa & P. aeruginosa & Undepleted & 21.56 & 11.69 & 15.25 & 1.80 \\
\hline & & & & Depleted & 33.24 & $\left(\sim 10^{4}\right)$ & 13.45 & \\
\hline S38 & Sputum & S. aureus & S. aureus & Undepleted & 20.76 & 6.87 & 23.83 & 3.17 \\
\hline & & $\& P$. aeruginosa & P. aeruginosa & Depleted & 27.63 & $\left(\sim 10^{2}\right)$ & 20.66 & \\
\hline S39 & Sputum & H. influenzae & H. influenzae & Undepleted & 23.82 & 11.18 & 14.45 & 2.79 \\
\hline & & & M. catarrhalis & Depleted & 35.00 & $\left(\sim 10^{3}\right)$ & 17.24 & \\
\hline $\mathbf{S 4 0}$ & ETA & MRSA & MRSA & Undepleted & 21.69 & 4.28 & 19.91 & 1.62 \\
\hline & & & & Depleted & 25.97 & $(\sim 19)$ & 18.29 & \\
\hline S41 & Sputum & H. influenzae & H. influenzae & Undepleted & 20.86 & 14.14 & 16.71 & 6.85 \\
\hline & & \& S. aureus & S. aureus & Depleted & 35.00 & $\left(\sim 10^{4}\right)$ & 23.56 & \\
\hline
\end{tabular}


Table 3. Resistance genes found by ARMA in relation to pathogens grown: Optimised pipeline (41 samples; 183 genes detected)

\begin{tabular}{|c|c|c|}
\hline ARMA vs. culture result & $\begin{array}{c}\text { No. } \\
\text { genes }\end{array}$ & Principal examples \\
\hline Gene endogenous in species & 26 & $\begin{array}{l}\text { Mostly efflux components; also blaoxA- } \\
\text { 50, aph(3')-Ilb and catB7 from } P \text {. } \\
\text { aeruginosa and aac(6')-Ic from } S \text {. } \\
\text { marcescens }\end{array}$ \\
\hline Match to observed R & 24 & $\begin{array}{l}\text { Variously including mecA in MRSA, } \\
\text { blaTEM in Enterobacteriaceae and } H . \\
\text { influenzae, also sul1 and } d f r \\
\text { determinants for E. coli }\end{array}$ \\
\hline $\begin{array}{l}\text { Partial match to observed } \\
\text { resistances }\end{array}$ & 4 & $\begin{array}{l}\text { Instances where blaTEM was found but } \\
\text { where MinION flagged an ESBL- } \\
\text { encoding variant, usually blaTEM-4, but } \\
\text { where the phenotype indicated only a } \\
\text { classical penicillinase, without oxyimino- } \\
\text { cephalosporin resistance }\end{array}$ \\
\hline $\begin{array}{l}\text { Unlikely match to observed } \\
\text { phenotype }\end{array}$ & 1 & $\begin{array}{l}P . \text { aeruginosa with bla TEM resistant to } \\
\text { piperacillin/tazobactam and ceftazidime } \\
\text { - see text }\end{array}$ \\
\hline $\begin{array}{l}\text { Possibly present, but relevant drug } \\
\text { not tested by clinical lab }\end{array}$ & 14 & $\begin{array}{l}\text { Commonly (i) where tet(C) found but lab } \\
\text { tested doxycycline, which is not a } \\
\text { substrate for this pump, or (ii) where } \\
\text { streptomycin, kanamycin and macrolide } \\
\text { determinants were found in gram- }\end{array}$ \\
\hline
\end{tabular}




\begin{tabular}{|c|c|c|}
\hline & & $\begin{array}{l}\text { negative bacteria but these drugs were } \\
\text { not tested, as not relevant to therapy. }\end{array}$ \\
\hline $\begin{array}{l}\text { Does not match phenotype of } \\
\text { isolate }\end{array}$ & 16 & $\begin{array}{l}\text { Mostly where bla TЕM (as bla TEM-4) was } \\
\text { recorded but the isolate (commonly } H \text {. } \\
\text { influenzae) was susceptible to } \\
\text { penicillins as well as cephalosporins, or } \\
\text { where tet(M) was found together with a } \\
\text { tetracycline-susceptible } S \text {. aureus }\end{array}$ \\
\hline $\begin{array}{l}\text { Genes unlikely to be from species } \\
\text { grown by the laboratory }\end{array}$ & 42 & $\begin{array}{l}\text { Mostly gram-positive-associated genes } \\
\text { when a gram-negative organism was } \\
\text { grown, or vice versa: commonly } \\
\text { including tet }(M) \text { and mefA }\end{array}$ \\
\hline $\begin{array}{l}\text { Gene recorded in a specimen with } \\
\text { no pathogen grown }\end{array}$ & 56 & $\begin{array}{l}\text { Mostly tet, mef mel, bla TEM-4 } \\
\text { determinants, likely to be associated } \\
\text { with normal flora }\end{array}$ \\
\hline Total & 183 & \\
\hline
\end{tabular}




\section{ONLINE METHODS}

\section{Ethics}

This study used excess respiratory samples, after routine microbiology diagnostic tests had been performed, from patients with suspected LRIs such as persistent (productive) cough, bronchiectasis, CAP/HAP, cystic fibrosis and exacerbation of chronic obstructive pulmonary disease (COPD, emphysema/chronic bronchitis). The UCL Infection DNA Bank (REC reference 12/LO/1089) approved use of excess respiratory samples for the study. No patient identifiable information was collected, hence informed consent was not required. The only data collected were routine microbiology results, which detailed the pathogen(s) identified and their antibiotic susceptibility profiles.

\section{Definitions}

'Respiratory pathogens' or 'pathogens' are defined in this study as common causes of respiratory infection, in order to differentiate them from commensal organisms. Respiratory pathogens identified in this study were: E. aerogenes, E. cloacae complex, E. coli, H. influenzae, K. oxytoca, K. pneumoniae, M. catarrhalis, P. mirabilis, P. aeruginosa, S. marcescens, S. aureus, S. pneumoniae, S. pyogenes. A list of all microorganisms identified in all samples tested using the optimised method (above our thresholds) are listed in supplementary table 8 . Some of these organisms, not defined as common pathogens here, could be considered pathogens in some clinical contexts.

\section{Routine clinical microbiological investigation}

Respiratory samples including sputum, endotracheal secretions and ETAs were treated with sputasol (Oxoid-SR0233) in a 1:1 ratio before being incubated for a minimum of $15 \mathrm{~min}$ at 37 ${ }^{\circ} \mathrm{C}$. Sputasol-treated respiratory samples $(10 \mu \mathrm{l})$ were inoculated into $5 \mathrm{ml}$ of sterile water and mixed (hence the limit of detection of culture is $10^{5} \mathrm{CFU} / \mathrm{ml}$ ). Following this, $10 \mu \mathrm{l}$ of sample was streaked onto blood, chocolate and cysteine lactose electrolyte deficient (CLED) agar. BAL samples were not treated with sputasol; instead they were centrifuged to 
concentrate bacterial cells for a minimum of $10 \mathrm{~min}$ at $3000 \mathrm{rpm}$. BALs did not undergo further dilution and were streaked directly onto the agar plate. Depending on clinical details and the source of the specimen, other agar plates (including sabouraud, mannitol salt and Burkholderia cepacia selective agar) were additionally used.

All inoculated agar plates were incubated at $37^{\circ} \mathrm{C}$ overnight and then examined for growth with the potential for re-incubation up to 48 hours. If any significant organism was grown, then antibiotic susceptibility testing by agar diffusion using EUCAST methodology was performed. The laboratory's Standard Operating Procedure is based on the Public Health England UK Standards for Microbiology Investigations B 57: Investigation of bronchoalveolar lavage, sputum and associated specimens ${ }^{51}$.

\section{Sample collection and storage}

The excess respiratory samples (sputa, ETA, BAL) were collected after culture and susceptibility testing at Norfolk and Norwich University Hospitals (NNUH) Microbiology Department (described above) and stored at $4{ }^{\circ} \mathrm{C}$ prior to testing. They were indicated by clinical microbiology to contain bacterial pathogen(s), NRF or to have yielded NSG. Forty samples ( $n=34$ positive and $n=6$ NRF samples, comprising 34 sputa, four BALs and two ETAs) were used to test the Pilot method and another 41 ( $n=29$ suspected LRI, $n=9$ NRF and $n=3$ NSG samples, comprising 38 sputa, one BAL and two ETAs) were used to test the Optimised pipeline.

\section{Pilot method: Host DNA Depletion}

Respiratory samples $(400 \mu \mathrm{l})$ were centrifuged at $8000 \mathrm{xg}$ for $5 \mathrm{~min}$, after which the supernatant was carefully removed and the pellet resuspended in $250 \mu \mathrm{l}$ of PBS. The saponin-based differential lysis method was modified from previously reported saponin methods ${ }^{33,52}$. Saponin (Tokyo Chemical Industry- S0019) was added to a final concentration of $2.5 \%$ (200 $\mu \mathrm{l}$ of $5 \%$ saponin), mixed well and incubated at room 
temperature (RT) for 10 min to promote host cell lysis. Following this incubation, $350 \mu$ of water was added and incubation was continued at RT for $30 \mathrm{~s}$, after which $12 \mu \mathrm{l}$ of $5 \mathrm{M} \mathrm{NaCl}$ was added to deliver an osmotic shock, lysing the damaged host cells. Samples were next centrifuged at $6000 \mathrm{xg}$ for $5 \mathrm{~min}$, with the supernatant removed and the pellet resuspended in $100 \mu$ l of PBS. HL-SAN buffer (5.5 M NaCl and $100 \mathrm{mM} \mathrm{MgCl}_{2}$ in nuclease-free water) was added (100 $\mu \mathrm{l})$ with $5 \mu \mathrm{l} \mathrm{HL-SAN} \mathrm{DNase} \mathrm{(25,000} \mathrm{units,} \mathrm{Articzymes} \mathrm{-} \mathrm{70910-202)} \mathrm{and}$ incubated for 15 min at $37^{\circ} \mathrm{C}$ with shaking at 800 RPM for host DNA digestion. An additional $2 \mu \mathrm{l}$ of HL-SAN DNase was added to the sample, which next was incubated for a further 15 min at $37^{\circ} \mathrm{C}$ with shaking at 800 RPM. Finally, the host-DNA depleted samples were washed three times with decreasing volumes of PBS $(300 \mu \mathrm{l}, 150 \mu \mathrm{l}, 50 \mu \mathrm{l})$. After each wash, the sample was centrifuged at $6000 \mathrm{xg}$ for $3 \mathrm{~min}$, the supernatant discarded and the pellet resuspended in PBS.

\section{Pilot method: Bacterial Lysis and DNA Extraction}

After the final wash step of the host depletion, the pellet was resuspended in $380 \mu$ of bacterial lysis buffer (Roche UK- 4659180001) and $20 \mu$ of proteinase K (>600mAu/ml) (Qiagen -19133) was added before incubation at $65^{\circ} \mathrm{C}$ for 10 min with shaking at 800 RPM (on an Eppendorf Thermomixer). Nucleic acid was then extracted from samples using the Roche MagNAPure Compact DNA_bacteria_V3_2 protocol (MagNA pure compact NA isolation kit I, Roche UK- 03730964001) on a MagNA Pure Compact machine (Roche UK$03731146001)$

\section{Optimised method: Host DNA Depletion (Figure 1)}

The optimized method sought to improve and shorten some steps. Specifically, after the first 5 min centrifugation at $8000 \times \mathrm{g}$, up to $50 \mu \mathrm{l}$ of supernatant was left so as not to disturb the pellet (final saponin conc. 2.2-2.5\%). Instead of performing two rounds of host DNA digestion, the amount of HL-SAN DNase was increased up to $10 \mu \mathrm{l}$ and a single incubation of 15 min at $37^{\circ} \mathrm{C}$ was carried out with shaking at 800 RPM on an Eppendorf Thermomixer. 
Finally, the number of washes was reduced to two with increasing volumes of PBS $(800 \mu \mathrm{l}$ and $1 \mathrm{ml}$ ).

\section{Optimised method: Bacterial Lysis and DNA Extraction (Figure 1)}

After the final wash, the pellet was re-suspended in $500 \mu$ l of bacterial lysis buffer (Roche UK - 4659180001), transferred to a bead-beating tube (Lysis Matrix E, MP Biomedicals 116914050) and bead-beaten at maximum speed (50 oscillations per second) for 3 min in a Tissue Lyser bead-beater (Qiagen - 69980). This ensured the release of DNA from difficultto-lyse organisms (e.g. S. aureus). The sample was centrifuged at 20,000 xg for $1 \mathrm{~min}$ and $\sim 230 \mu$ of supernatant was transferred to a fresh Eppendorf tube. The volume was toppedup with $170 \mu \mathrm{l}$ of bacterial lysis buffer and $20 \mu \mathrm{l}$ of proteinase K (>600 mAu/ml, Qiagen 19133) was added. Samples were then incubated at $65^{\circ} \mathrm{C}$ for 5 min with shaking at 800 RPM on an Eppendorf Thermomixer. DNA was extracted from samples using the Roche MagNAPure Compact DNA_bacteria_V3_2 protocol (MagNA pure compact NA isolation kit I, Roche UK - 03730964001) on a MagNA Pure Compact machine (Roche UK $03731146001)$

\section{DNA quantification and quality control}

DNA quantification was performed using the high sensitivity dsDNA assay kit (Thermo Fisher - Q32851) on the Qubit 3.0 Fluorometer (Thermo Fisher - Q33226). DNA quality and fragment size (PCR products and MinION libraries) were assessed using the TapeStation 2200 (Agilent Technologies - G2964AA) automated electrophoresis platform with the Genomic ScreenTape (Agilent Technologies - 5067-5365) and a DNA ladder (200 to $>60,000$ bp, Agilent Technologies - 5067-5366).

\section{MinION Library Preparation and Sequencing}

MinION library preparation was performed according to the manufacturer's instructions for (i) the Rapid Low-Input by PCR Sequencing Kit (SQK-RLI001), (ii) the Rapid Low-Input 
Barcoding Kit (SQK-RLB001) or (iii) the Rapid PCR Barcoding Kit (SQK-RPB004) with minor alterations as follows. For single sample sequencing runs using the SQK-RLI001 kit, $10 \mathrm{ng}$ of the MagNA Pure-extracted DNA were used for the tagmentation/fragmentation reaction, where DNA was incubated at $30^{\circ} \mathrm{C}$ for $1 \mathrm{~min}$ and at $75^{\circ} \mathrm{C}$ for $1 \mathrm{~min}$. The PCR reaction was run as per the manufacturer's instructions; however, the number of PCR cycles was increased to 20. For multiplexed runs, SQK-RLB001 and SQK-RPB004 kits were used. A 1.2x AMPure XP bead (Beckman Coulter-A63881) wash was introduced after the MagNA Pure DNA extraction and prior to library preparation for multiplexed runs and DNA was eluted in $15 \mu \mathrm{l}$ of nuclease-free water. Modifications for the library preparation were i) $10 \mathrm{ng}$ of input DNA and $2.5 \mu \mathrm{l}$ of FRM were used for the tagmentation/fragmentation reaction and nuclease-free water was used to make the volume up to $10 \mu \mathrm{l}$, ii) for the PCR reaction, 25 cycles were used and the reaction volume was doubled. All samples run using the Pilot method used a 6 min extension time, whereas the Optimised method used a reduced extension time of $4 \mathrm{~min}$. When multiplexing, PCR products were pooled together in equal concentrations, then subjected to a $0.6 x$ AMPure XP bead wash and eluted in $14 \mu$ of the buffer recommended in the manufacturer's instructions $(10 \mu \mathrm{L} 50 \mathrm{mM} \mathrm{NaCl}, 10 \mathrm{mM}$ Tris. $\mathrm{HCl}$ $\mathrm{pH}$ 8.0). Sequencing was performed on the MinION platform using R9.4, R9.5 or R9.4.1 flow cells. The library (50-300 fmol) was loaded onto the flow cell according to the manufacturer's instructions. ONT MinKNOW software (versions 1.4-1.13.1) was used to collect raw sequencing data and ONT Albacore (versions 1.2.2-2.1.10) was used for local base-calling of the raw data after sequencing runs were completed. The MinION was run for up to 48 hours with WIMP/ARMA analysis performed on the first six folders ( 24,000 reads) for Pilot method samples and the first two hours of data for all Optimised method samples.

\section{Quantitative PCR (qPCR) assays}

Probe or SYBR Green based qPCR was performed on samples to detect and quantify human DNA, DNA targets for specific pathogens (E. coli, H. influenzae, K. pneumoniae, $M$. catarrhalis, P. aeruginosa, S. aureus, Stenotrophomonas maltophilia, S. pneumoniae and S. 
pyogenes) and the bacterial 16S rRNA V3-V4 gene fragment. All qPCR assays were performed on a Light Cycler ${ }^{\circledR} 480$ Instrument (Roche). Details of primer sequences and targets can be found in Supplementary Table 9 (oligonucleotides were supplied by Sigma.

For all probe-based qPCR reactions, the master mix consisted of $10 \mu \mathrm{l}$ LightCycler 480 probe master (2X), $0.5 \mu \mathrm{l}$ each of reverse and forward primer (final conc. $0.25 \mu \mathrm{M}$ ) and $0.4 \mu \mathrm{l}$ probe (final conc. $0.2 \mu \mathrm{M}$ ). For all SYBR-Green-based qPCR reactions, the master mix consisted of $10 \mu$ L LightCycler 480 SYBR Green I master (2x) and $1 \mu$ of each forward and reverse primer (final conc. $0.5 \mu \mathrm{M}$ ). To the PCR mix, $2 \mu$ of DNA template and nuclease-free water to a total volume of $20 \mu \mathrm{l}$ were added. The qPCR conditions were: pre-incubation at $95{ }^{\circ} \mathrm{C}$ for $5 \mathrm{~min}$, amplification for 40 cycles at $95{ }^{\circ} \mathrm{C}$ for $30 \mathrm{sec}, 55^{\circ} \mathrm{C}$ for $30 \mathrm{sec}$ and $72{ }^{\circ} \mathrm{C}$ for $30 \mathrm{sec}$, with a final extension at $72{ }^{\circ} \mathrm{C}$ for $5 \mathrm{~min}$. Melt curves analysis (for SYBR-Green qPCR) was performed at $95{ }^{\circ} \mathrm{C}$ for $5 \mathrm{sec}, 65^{\circ} \mathrm{C}$ for $1 \mathrm{~min}$, ramping to $95{ }^{\circ} \mathrm{C}$ at $0.03{ }^{\circ} \mathrm{C} / \mathrm{s}$ in continuous acquisition mode, followed by cooling to $37^{\circ} \mathrm{C}$. All probe-based confirmatory qPCR used the following conditions: pre-incubation at $95{ }^{\circ} \mathrm{C}$ for $15 \mathrm{~min}$, amplification for 40 cycles at $94{ }^{\circ} \mathrm{C}$ for $15 \mathrm{sec}$ and $60^{\circ} \mathrm{C}$ for $1 \mathrm{~min}$.

\section{Example Limit of detection}

The LoD of the Optimised method was determined for the detection of one Gram-positive and one Gram-negative bacteria in sputum using serial dilutions $\left(10-10^{5} \mathrm{cfu} / \mathrm{ml}\right)$ of cultured E. coli (H141480453) and S. aureus (NCTC 6571) spiked into NRF sputum samples with high and low bacterial commensal backgrounds (as determined by $16 \mathrm{~S}$ qPCR). The serial dilutions were made in sterile PBS and plated in triplicate on LB agar to determine colony forming units (CFU) per ml. The same dilutions were used to spike an NRF sputum sample for LoD experiments. Detection and quantification of bacterial DNA was performed using probe-based qPCR assays and MinION sequencing. 


\section{Mock community experiments}

Clinical isolates from respiratory samples were used to generate a mock community consisting of S. pneumoniae, K. pneumoniae, $H$. influenzae, S. maltophilia and $P$. aeruginosa. E. coli and S. aureus strains were also included (H141480453 and NCTC 6571 respectively). Pathogens (E. coli and S. aureus in $10 \mathrm{ml}$ Luria-Broth and K. pneumoniae, P. aeruginosa and S. maltophilia in $10 \mathrm{ml}$ Tryptic Soy Broth (TSB)) were cultured overnight at $37^{\circ} \mathrm{C}$ with shaking at 180 RPM. $H$. influenzae (in $10 \mathrm{ml} \mathrm{TSB}$ ) and S. pneumoniae (in $10 \mathrm{ml}$ Brain Heart Infusion Broth) were cultured statically at $37{ }^{\circ} \mathrm{C}$ with $5 \% \mathrm{CO}_{2}$ in an aerobic incubator. Cultured pathogens were then spiked into an NRF sample ( $10^{3}-10^{6} \mathrm{CFU} /$ pathogen). The spiked samples were then tested in triplicate with the Optimised method, to determine if saponin depletion resulted in any inadvertent lysis of pathogens and loss of their DNA. All spiked samples were processed alongside undepleted controls. Probe or SYBR Green-based qPCR assays were used to determine the relative quantity of each spiked pathogen in depleted and undepleted spiked sputum samples.

\section{Human read removal}

Human reads were removed from basecalled FASTQ files using minimap2 to align to the human hg38 genome (GCA_000001405.15 "soft-masked" assembly) prior to Epi2ME analysis. Only unassigned reads were exported to a bam file using Samtools (-f 4 parameter). Non-human reads were converted back to FASTQ format using bam2fastx. These FASTQ files were processed for pathogen identification using WIMP and antibiotic resistance gene detection with ARMA. Further downstream analysis for genome coverage was performed using minimap2 with default parameters for long-read data (-a -x map-ont) and visualised using qualimap (used for time-point analysis).

\section{Pathogen identification and antibiotic resistance gene detection}

The EPI2ME Antimicrobial Resistance pipeline (ONT, versions 2.59.1896509) was used for initial analysis of MinION data for the identification of bacteria present in the sample and any 
associated antimicrobial resistance genes. Within this pipeline, WIMP (What's in my Pot rev. 3.3.1) supports the identification of bacteria, viruses, fungi, archaea and human reads and was used for respiratory pathogen identification. WIMP utilises 'Centrifuge', a k-merbased read identification tool based on a Burrows-Wheeler transform and the FerraginaManzini index, to identify reads using the RefSeq database ${ }^{53}$. ARMA (Antimicrobial Resistance Mapping Application - rev. 1.1.5) is also included in the Antimicrobial Resistance pipeline. ARMA utilises the CARD database for antibiotic resistance gene detection and identification by aligning input reads using minimap2 (alignments reported at $>75 \%$ accuracy and $>40 \%$ horizontal coverage ${ }^{54}$ ). Full manuals are publicly available for WIMP and ARMA on the ONT website (https://nanoporetech.com/EPI2ME-amr). NanoOK/NanoOK RT ${ }^{45,55}$ are publically available tools which identify microbes and antimicrobial resistance using basecalled nanopore data, providing similar outputs to those from ONTs WIMP and ARMA software.

Initial analysis of respiratory metagenomic data revealed that thresholds would be required to improve the accuracy of results. Thresholds, in terms of number of bacteria per $\mathrm{ml}$ of body fluid, are applied in clinical microbiology laboratories for some infections including those of the urinary and respiratory tracts. The same approach was required for metagenomics. The clinical thresholds used for respiratory samples is typically $10^{5}$ pathogens $/ \mathrm{ml}$ (range $10^{3}$ $10^{5} / \mathrm{ml}$ dependent on sample type) and is achieved by sample dilution ${ }^{51}$. We routinely applied thresholds at $\geq 1 \%$ of classified reads, with a WIMP assignment q-score $\geq 20$ (within .csv files). We chose these thresholds to: censor reads arising from pipeline contaminants; remove barcode leakage between samples on multiplexed runs (ONT's Flongle (https://nanoporetech.com/products/comparison), an adapter for single use flowcells designed for diagnostic applications, should overcome this issue) and; remove low quality WIMP alignments, which result in misclassified reads. Antibiotic resistance genes were reported if $>1$ gene alignment was present using the 'clinically relevant' parameter within 
ARMA. This parameter currently reports resistance genes, acquired and chromosomal, but not resistance mutations/SNPs.

\section{Pathobiont-specific gene analysis}

Species-specific gene alignments were performed on samples positive for $H$. influenzae or $S$. pneumoniae by metagenomics (above our thresholds). Reads (after human DNA removal) were aligned to pathobiont-specific genes (siaT, ply - chosen from a literature search for species-specific genes in $H$. influenzae ${ }^{56}$ and S. pneumoniae ${ }^{15}$, respectively) using minimap2 with default parameters for long-read data (-a -x map-ont) and the number of mapped reads visualised using qualimap. If a sample contained $>1$ copy of the specific gene it was considered positive for the species.

\section{Bacterial genome assembly}

Genome assembly was performed first using Fast5-to-Fastq to remove reads shorter than $2000 \mathrm{bp}$ and with a mean quality score lower than seven (https://github.com/rrwick/Fast5-toFastq). Porechop was used to remove sequencing adapters in the middle and/or the ends of each read, and re-identification of barcodes was carried out for each multiplexed sample (v0.2.3) (https://github.com/rrwick/Porechop). Filtered reads were aligned to a reference genome (chosen based on WIMP classification of pathogen reads) using minimap2 with default parameters for ONT long-read data (v2.6-2.10) ${ }^{57}$. Finally, Canu was used to assemble mapped reads into contigs using this long-read sequence correction and assembly tool (v1.6) ${ }^{58,59}$. BLAST Ring Image Generator (BRIG) was used for BLAST comparisons of the genome assemblies generated ${ }^{60}$.

\section{Data availability}

All clinical sample sequence data and assemblies are available via European Nucleotide Achive (ENA) under study accession number PRJEB30781. 


\section{References}

51. Services, M. UK Standards for Microbiology Investigations. Investigation of bronchoalveolar lavage, sputum and associated specimens. Bacteriology B57, 38 (2018).

52. Anscombe, C., Misra, R.V. \& Gharbia, S. Whole genome amplification and sequencing of low cell numbers directly from a bacteria spiked blood model. bioRxiv (2018). 53. Kim, D., Song, L., Breitwieser, F.P. \& Salzberg, S.L. Centrifuge: rapid and sensitive classification of metagenomic sequences. bioRxiv (2016).

54. Jia, B. et al. CARD 2017: expansion and model-centric curation of the comprehensive antibiotic resistance database. Nucleic Acids Research 45, D566-D573 (2017).

55. Leggett, R.M., Heavens, D., Caccamo, M., Clark, M.D. \& Davey, R.P. NanoOK: multi-reference alignment analysis of nanopore sequencing data, quality and error profiles. Bioinformatics 32, 142-144 (2015).

56. Price, E.P. et al. Simultaneous identification of Haemophilus influenzae and Haemophilus haemolyticus using real-time PCR. Future microbiology 12, 585-593 (2017). $57 . \quad \mathrm{Li}, \mathrm{H}$. Minimap2: pairwise alignment for nucleotide sequences. Bioinformatics, bty191-bty191 (2018).

58. Koren, S., Walenz, B.P., Berlin, K., Miller, J.R. \& Phillippy, A.M. Canu: scalable and accurate long-read assembly via adaptive k-mer weighting and repeat separation. bioRxiv (2016).

59. Koren, S. et al. Complete assembly of parental haplotypes with trio binning. bioRxiv (2018).

60. Alikhan, N.-F., Petty, N.K., Ben Zakour, N.L. \& Beatson, S.A. BLAST Ring Image

Generator (BRIG): simple prokaryote genome comparisons. BMC Genomics 12, 402 (2011). 